\title{
Nocturnal assisted ventilation using bilevel positive airway pressure: the effect of expiratory positive airway pressure
}

\author{
M.W. Elliott, A.K. Simonds
}

Nocturnal assisted ventilation using bilevel positive airway pressure: the effect of expiratory positive airway pressure. M.W. Elliott, A.K. Simonds. (CERS Journals Ltd 1995. ABSTRACT: Increasing expiratory positive airway pressure (EPAP) has theoretical advantages during overnight nasal ventilation. We wanted to evaluate the effect of the addition of EPAP upon the control of nocturnal hypoventilation.

Seven patients with neuromuscular/skeletal (NMS) disorder (mean \pm sD forced vital capacity $(\mathrm{FVC}) \mathbf{1 . 0 6} \pm 0.28 l$, arterial oxygen tension $\left(\mathrm{PaO}_{2}\right) 9.1 \pm 0.6 \mathrm{kPa}$, and arterial carbon dioxide tension $\left.\left(\mathrm{PaCO}_{2}\right) 6.9 \pm 0.9 \mathrm{kPa}\right)$, and seven patients with chronic obstructive pulmonary disease (COPD) $\left(\mathrm{FEV}_{1} \mathrm{0.46}_{0.0 .14} \mathrm{l}, \mathrm{PaO}_{2} 6.2 \pm 0.6 \mathrm{kPa}\right.$, and $\mathrm{PaCO}_{2} 8.4 \pm 1.1 \mathrm{kPa}$ ) all underwent full polysomnography on two nights during bilevel positive airway pressure (BiPAP) ventilation, with and without the addition of expiratory positive airway pressure, which was matched to the level of dynamic positive end-expiratory pressure (PEEP) or set at a minimum value of $5 \mathbf{c m H}_{2} \mathrm{O}$.

In the group with neuromuscular/skeletal disorders the maximum transcutaneous carbon dioxide tension $\left(\mathrm{PtcCO}_{2}\right)$ overnight was lower (inspiratory positive airway pressure (IPAP) $8.1 \pm 1.4 \mathrm{kPa}$, IPAP/EPAP $7.3 \pm 0.9 \mathrm{kPa}$ ) and the minimum level of arterial oxygen saturation $\left(\mathrm{SaO}_{2} \mathrm{~min}\right)$ increased (IPAP 77.1 $\pm 6.7 \%$, IPAP/EPAP $83.6 \pm 4.2 \%$ ) when expiratory positive airway pressure was added. There were no differences in mean PtcCO $\mathrm{Cr}_{2}$ mean oxygen saturation, but sleep quality was worse (non-rapid eye movement (non-REM) sleep IPAP 266 \pm 44 min, IPAP/EPAP 226 \pm 32 min). In the patients with COPD, expiratory positive airway pressure conferred no advantage.

In conclusion, $5 \mathrm{cmH}_{2} \mathrm{O}$ expiratory positive airway pressure improved the control of nocturnal hypoventilation in patients with neuromuscular/skeletal disorders, but not in patients with COPD. However, expiratory positive airway pressure may have a deleterious effect upon sleep quality in some patients.

Eur Respir J., 1995, 8, 436-440.

Dept of Thoracic Medicine, The Royal Brompton National Heart and Lung Hospitals (Chelsea), London, UK.

Correspondence: M.W. Elliott St James's University Hospital

Beckett Street

Leeds LS9 7TF

UK

Keywords: Nasal intermittent positive pressure ventilation

nocturnal hypoventilation

obstructive lung diseases

Received: June 291993

Accepted after revision January 21995
Theoretically, the addition of expiratory positive airway pressure (EPAP) may improve gas exchange during overnight nasal ventilation. In patients with neuromuscular/skeletal (NMS) disorders, the compliance of the lung [1,2] and chest wall [1,3] is decreased, and positive pressure during expiration may increase respiratory system compliance [4]. Patients with obstructive airways disease may have a positive elastic recoil pressure at the end of expiration, so-called intrinsic positive end-expiratory pressure (PEEPi). This acts as an inspiratory threshold load and increases inspiratory muscle effort [5]. The addition of positive pressure during expiration has been shown to improve diaphragmatic function [6] and decrease the mechanical work of breathing during patient-triggered ventilation [7], by counterbalancing and reducing this inspiratory threshold load.

During controlled mechanical ventilation, the addition of PEEP has been shown to improve gas exchange in intubated patients with acute respiratory failure due to chronic obstructive pulmonary disease (COPD) [8]. The bilevel positive airway pressure (BiPAP) functions in the assist/control mode, and the addition of EPAP may improve arterial blood gas tensions in patients with COPD by beneficial effects upon lung mechanics for assisted breaths and during controlled ventilation by improving the ventilation/perfusion $(\mathrm{V} / \mathrm{Q})$ ratio [8].

We have, therefore, investigated the effect of EPAP upon overnight gas exchange during nasal ventilation both in patients with NMS disorders and patients with COPD.

\section{Patients and methods}

Patient functional data are given in table 1. Arterial blood gas tensions were measured using a Corning 178 blood gas analyser (Ciba-Corning Ltd, Halstead, Essex, UK), and spirometry was measured in the hospital clinical laboratory using a Spiroflow Spirometer (P.K. Morgan Ltd, Rainham, Kent, UK). Subjects had chronic ventilatory failure and, in each respiratory status, had been stabilized with domiciliary nasal ventilation using a volume cycled flow generator. In all cases, the arterial 
Table 1. - Functional data of patients

\begin{tabular}{|c|c|c|c|c|c|c|c|c|c|c|}
\hline $\begin{array}{l}\text { Patient } \\
\text { No. }\end{array}$ & $\begin{array}{l}\text { Age } \\
\text { yrs }\end{array}$ & Sex & Diagnosis & $\begin{array}{c}\mathrm{FEV}_{1} / \mathrm{FVC} \\
l\end{array}$ & $\mathrm{pH}$ & $\begin{array}{l}\mathrm{PaO}_{2} \\
\mathrm{kPa}\end{array}$ & $\begin{array}{c}\mathrm{PaCO}_{2} \\
\mathrm{kPa}\end{array}$ & $\begin{array}{l}\text { PEEPi } \\
\mathrm{cmH}_{2} \mathrm{O}\end{array}$ & $\begin{array}{l}\text { IPAP } \\
\mathrm{cmH}_{2} \mathrm{O}\end{array}$ & $\begin{array}{l}\text { EPAP } \\
\mathrm{cmH}_{2} \mathrm{O}\end{array}$ \\
\hline 1 & 46 & M & Kyphoscoliosis & $0.85 / 0.95$ & 7.37 & 9.2 & 6.7 & 0 & 16 & 5 \\
\hline 2 & 58 & M & Kyphoscoliosis & $0.75 / 1.20$ & 7.40 & 8.9 & 7.4 & +1.0 & 20 & 5 \\
\hline 3 & 54 & M & Polyneuropathy & $0.85 / 1.15$ & 7.37 & 9.2 & 7.4 & 0 & 20 & 5 \\
\hline 4 & 54 & M & Previous polio & $0.94 / 1.45$ & 7.46 & 9.5 & 5.4 & ND & 20 & 5 \\
\hline 5 & 58 & $\mathrm{~F}$ & Previous polio & $0.45 / 0.5$ & 7.45 & 9.9 & 6.7 & ND & 16 & 5 \\
\hline 6 & 46 & M & Kyphoscoliosis & $0.9 / 0.95$ & 7.40 & 8.9 & 7.9 & 0 & 20 & 5 \\
\hline 7 & 58 & M & Kyphoscoliosis & $0.75 / 1.35$ & 7.40 & 8.7 & 6.3 & ND & 20 & 5 \\
\hline 8 & 68 & $\mathrm{~F}$ & COPD & $0.55 / 1.15$ & 7.39 & 6.7 & 8.7 & ND & 20 & 5 \\
\hline 9 & 71 & M & COPD & $0.57 / 2.97$ & 7.40 & 6.8 & 9.2 & ND & 20 & 5 \\
\hline 10 & 66 & M & COPD & $0.4 / 1.81$ & 7.33 & 6.2 & 8.0 & +4.0 & 20 & 5 \\
\hline 11 & 64 & $\mathrm{~F}$ & COPD & $0.30 / 0.80$ & 7.39 & 6.3 & 7.5 & +6.1 & 20 & 6 \\
\hline 12 & 61 & M & COPD & $0.68 / 2.55$ & 7.46 & 5.3 & 7.2 & +7.6 & 20 & 8 \\
\hline 13 & 54 & M & COPD & $0.36 / 1.95$ & 7.32 & 6.6 & 10.5 & +12.2 & 20 & 12 \\
\hline 14 & 65 & M & COPD & $0.33 / 2.04$ & 7.34 & 5.3 & 7.9 & +9.8 & 20 & 10 \\
\hline
\end{tabular}

COPD: chronic obstructive pulmonary disease; PEEPi: intrinsic positive end-expiratory pressure; IPAP: inspiratory positive airway pressure; EPAP: expiratory positive airway pressure; M: male; F: female; ND: not determined; $\mathrm{FEV}_{1}$ : forced expiratory volume in one second; FVC: forced vital capacity; $\mathrm{PaO}_{2}$ : arterial oxygen tension; $\mathrm{PaCO}_{2}$ : arterial carbon dioxide tension.

blood gas tensions at the time of the study were better than those at first presentation.

All patients gave informed consent to the study and were already receiving nasal ventilation at home. They were, therefore, familiar with the technique, mask, etc., and were acclimatized to the BiPAP ventilator (BiPAP, Respironics Inc., Monroeville, Pennsylvania, USA) during wakefulness over a period of approximately $3 \mathrm{~h}$. During this time, they also experienced the addition of EPAP. Inspiratory positive airway pressure (IPAP) was set to the maximum tolerated level. Respironics nasal masks were used throughout. No changes to drug therapy were made between the two studies.

In nine patients (four NMS and five COPD), oesophageal pressure (Poes) was measured, with the patient lying semi-supine, using a balloon-tipped catheter $100 \mathrm{~cm}$ in length (PK Morgan, Rainham, Kent, UK) positioned in the standard manner [9], and connected to a Validyne MP45-1 differential pressure transducer (range \pm 250 $\mathrm{cmH}_{2} \mathrm{O}$; Validyne Corp, Northridge, CA, USA), calibrated before each study and referenced to atmospheric pressure. Airflow was recorded at the mouth using a Fleisch No. 4 pneumotachograph head (Fleisch, Lausanne, Switzerland), connected to a Mercury CS6 electrospirometer (Mercury Electronics, Glasgow, UK). All signals were recorded on paper by a Mingograf 800 inkjet recorder (Siemens-Elema AB, Stockholm, Sweden). The level of dynamic PEEPi was subsequently measured as the difference between the end-expiratory oesophageal pressure (EEPoes) and the Poes at the onset of inspiratory airflow [10]. In these patients, EPAP was set at the level of PEEPi recorded during spontaneous ventilation, with a minimum pressure of $5 \mathrm{cmH}_{2} \mathrm{O}$. In the patients in whom balloons were not passed, EPAP was set at 5 $\mathrm{cmH}_{2} \mathrm{O}$. Patients were ventilated with air using the spontaneous/timed mode throughout the study.

Full polysomnography was performed on two consecutive nights. On one night, patients received IPAP with the minimum level of EPAP (I night), and on the other night the same level of IPAP was delivered, but with the level of EPAP described above (IE night). It should be noted that an increase in EPAP reduces the differential pressure between inspiration and expiration, because EPAP is included in IPAP and not added to it. The order of the studies was randomized. All patients had had previous sleep studies and were familiar with the sleep laboratory. The electroencephalogram and electro-oculograms were recorded using silver cup electrodes and standard lead placements [11], and the submental electromyogram

\begin{tabular}{lccc} 
& IPAP & IPAP/EPAP & p-value \\
& min & min & \\
\hline NMS & & & \\
TST & $321 \pm 43$ & $280 \pm 73$ & 0.15 \\
Wake & $63 \pm 28$ & $95 \pm 56$ & 0.15 \\
Stage 1 & $40 \pm 16$ & $50 \pm 17$ & 0.15 \\
Stage 2 & $203 \pm 43$ & $158 \pm 47$ & 0.04 \\
NREM & $266 \pm 44$ & $226 \pm 32$ & 0.05 \\
Max NREM & $54 \pm 21.7$ & $49.7 \pm 19.2$ & 0.68 \\
REM & $56 \pm 31$ & $55 \pm 56$ & 0.80 \\
Max REM & $23.6 \pm 10.9$ & $17.5 \pm 15.3$ & 0.27 \\
Arousals & $16.6 \pm 8.5$ & $21.3 \pm 7.8$ & 0.18 \\
COPD & & & \\
TST & $229 \pm 123$ & $254 \pm 75$ & 1.0 \\
Wake & $152 \pm 73$ & $170 \pm 96$ & 0.8 \\
Stage 1 & $49 \pm 25$ & $47 \pm 20$ & 1.0 \\
Stage 2 & $158 \pm 68$ & $148 \pm 96$ & 1.0 \\
NREM & $220 \pm 58$ & $204 \pm 88$ & 1.0 \\
Max NREM & $42.9 \pm 16.6$ & $45.7 \pm 14.9$ & 0.83 \\
REM & $34 \pm 14$ & $25 \pm 48$ & 0.59 \\
Max REM & $13.6 \pm 6.2$ & $7 \pm 9$ & 0.12 \\
Arousals & $17.7 \pm 6.0$ & $16.3 \pm 1.8$ & 0.79 \\
\hline
\end{tabular}

TST: total sleep time; NMS: neuromuscular/skeletal disorders; REM: rapid eye movement sleep; NREM: non-rapid eye movement sleep; Max NREM and Max REM: longest periods of uninterrupted NREM and REM sleep, respectively. For further abbreviations see legend to table 1 . 
using surface electrodes. Arterial oxygen saturation $\left(\mathrm{SaO}_{2}\right)$ was measured continuously at the earlobe with an Ohmeda Biox III pulse oximeter (Ohmeda Ltd, Louisville, USA), and transcutaneous carbon dioxide $\left(\mathrm{PtcCO}_{2}\right)$ by a Hewlett Packard capnometer (Hewlett Packard, Waltham, MA, USA) with the sensor placed on the forearm. All signals were stored onto a Neuroscience Neuromapper (Neuroscience Ltd, Harold Hill, Essex, UK). Studies started at 11 p.m. and continued for $8 \mathrm{~h}$, or until the patient woke and expressed a desire to get up. Staging of each $30 \mathrm{~s}$ epoch was performed manually using standard criteria [11]. Wilcoxon tests were used to compare IPAP and IPAP/EPAP, with the level of significance set at the value
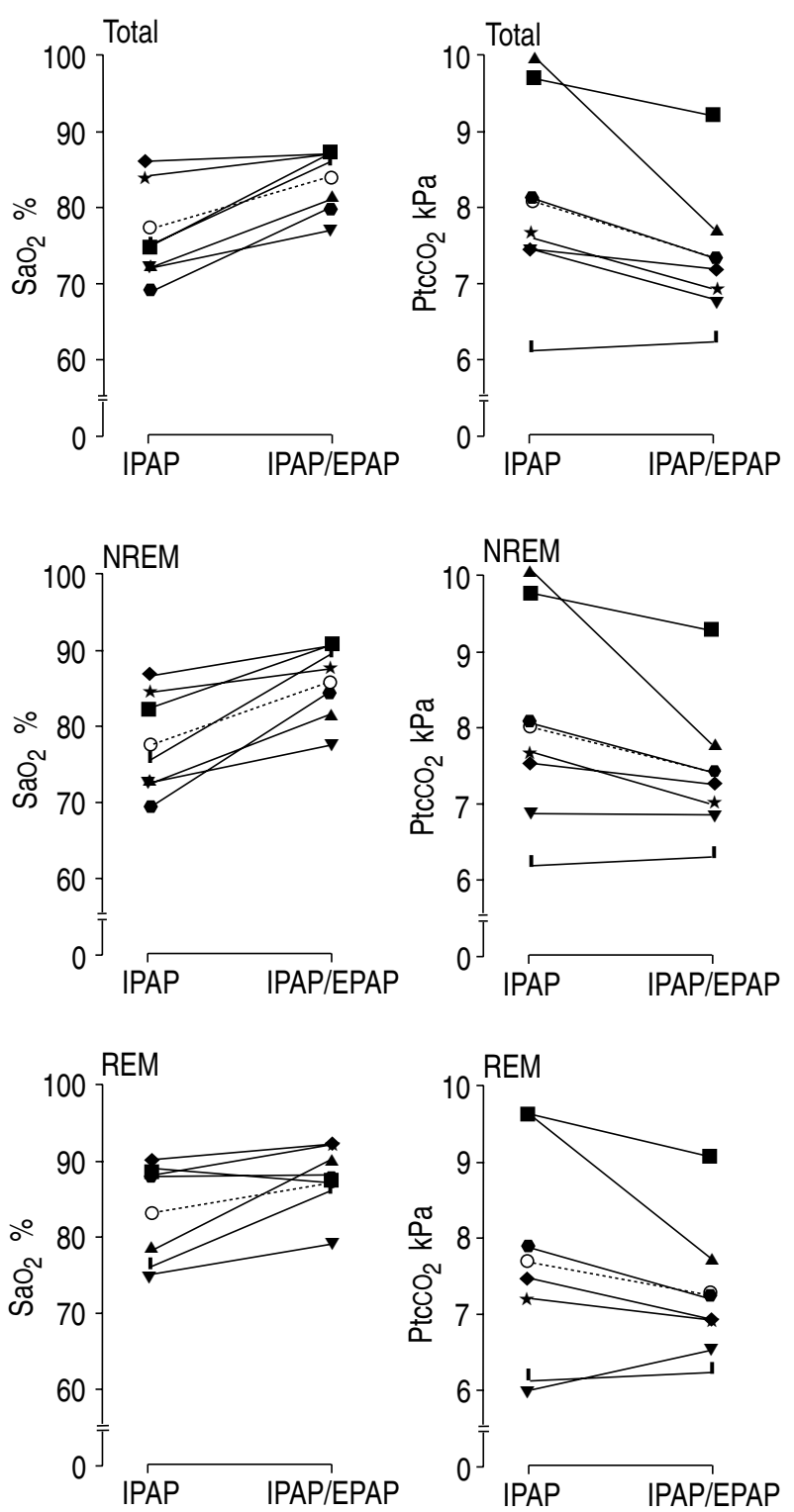

Fig. 1 - The minimum $\mathrm{SaO}_{2}$ and the maximum $\mathrm{PtcCO}_{2}$ overnight, during non-REM sleep and during REM sleep in the NMS patients. Dotted lines and open circles represent group mean data. $\mathrm{SaO}_{2}$ : arterial oxygen saturation; $\mathrm{PtcCO}_{2}$ : transcutaneous carbon dioxide tension; REM: rapid eye movement; NMS: neuromuscular/skeletal disorders; IPAP: inspiratory positive airway pressure; EPAP: expiratory positive airway pressure. $\downarrow$ : subject No. $1 ; \star$ : subject No. 2 ; $\boldsymbol{\Delta}$ : subject No. $3 ; \boldsymbol{\nabla}$ : subject No. 4; : subject No. 5; $\mathbf{\square}$ : subject No. 6; ' : subject No. 7. Note that the vertical axis is cut-off from zero. of $\mathrm{p}$ less than 0.05 .

\section{Results}

There were differences in sleep quality between the two studies in the NMS group, with significantly less stage 2 sleep when EPAP was added, but not in the COPD group (table 2).

In patients with NMS disorders, there were no differ-

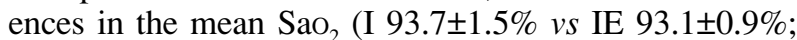
$\mathrm{p}=0.3$ ) or mean $\mathrm{PtcCO}_{2}$ (I $7.1 \pm 0.9 \mathrm{kPa}$ s IE $6.9 \pm 0.9 \mathrm{kPa}$; $\mathrm{p}=0.35$ ) overnight or during any sleep stage. However, when EPAP was added the maximum $\mathrm{PtcCO}_{2}\left(\mathrm{PtcCO}_{2} \max \right)$ was lower (I 8.1 $\pm 1.4 \mathrm{kPa}$ vs IE $7.3 \pm 0.9 \mathrm{kPa} ; \mathrm{p}=0.04$ )
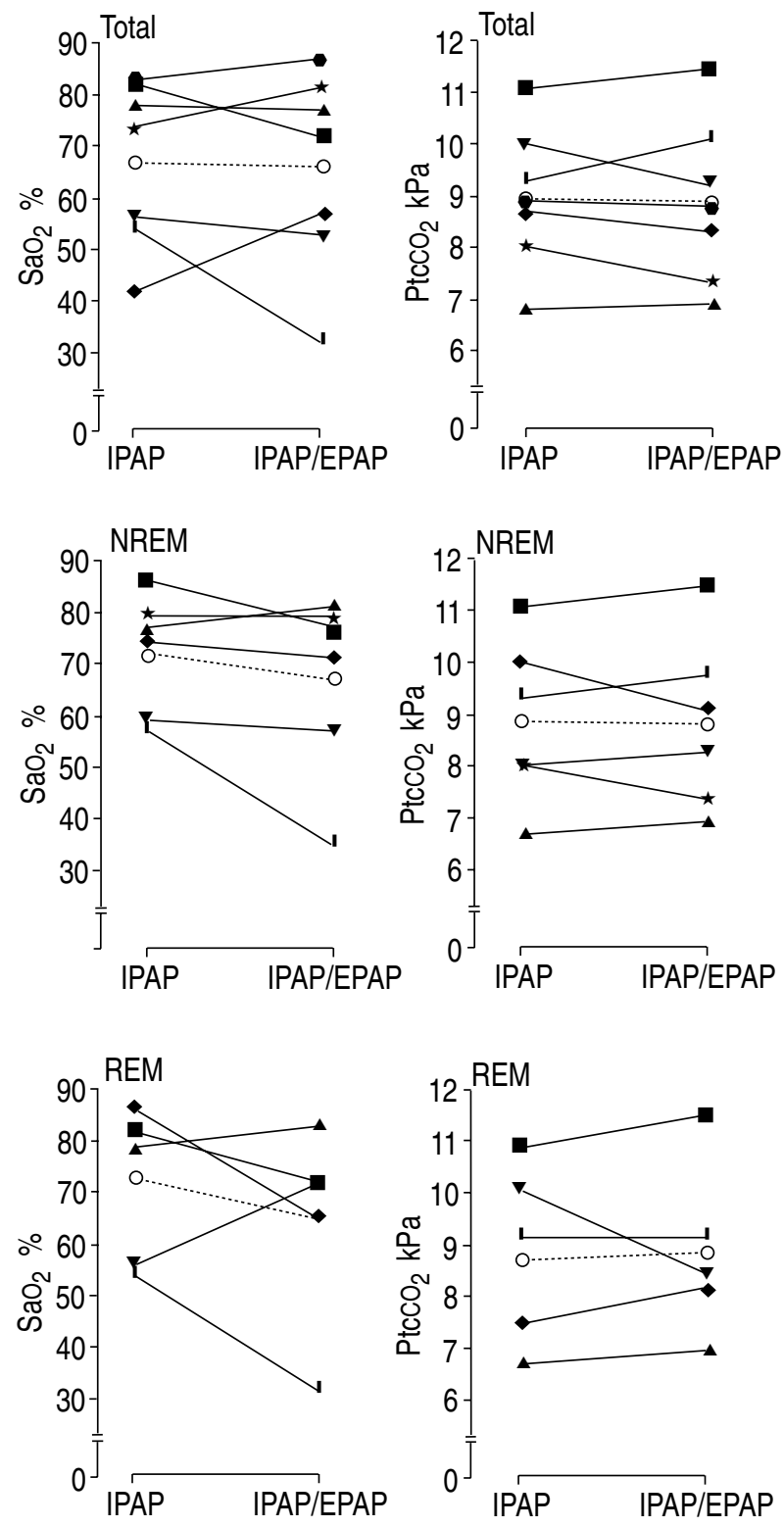

Fig. 2. - The minimum $\mathrm{SaO}_{2}$ and the maximum $\mathrm{PtcCO}_{2}$ overnight, during non-REM sleep and during REM sleep in the COPD patients. Dotted lines and open circles represent group mean data. COPD: chronic obstructive pulmonary disease. For further abbreviations see legend to figure $1 . \quad$ : subject No. $8 ; \boldsymbol{\nabla}:$ subject No. $9 ; \star$ : subject No. $10 ; \bullet:$ subject No. $11 ; \boldsymbol{\Delta}$ : subject No. $12 ; \mathbf{\square}$ : subject No. $13 ; \mathbf{I}$ : subject No. 14. Note that the axis is cut-off from zero. 
and the minimum level of saturation $\left(\mathrm{SaO}_{2} \mathrm{~min}\right)$ increased (I 77.1 $\pm 6.7 \%$ vs IE 83.6 $\pm 4.2 \%$; p=0.02) (fig. 1). During wakefulness, $\mathrm{PtcCO}_{2}$ max was lower when EPAP was added (I 7.9 $\pm 1.2 \mathrm{kPa} v s$ IE $7.3 \pm 0.9 \mathrm{kPa} ; \mathrm{p}=0.04$ ). During

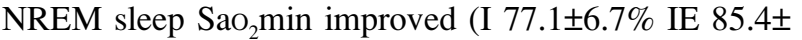
$5.0 \% ; \mathrm{p}=0.02)$. $\mathrm{PtcCO}_{2} \max$ was lower with the addition of EPAP in 5 of the 7 patients, but overall this did not quite reach statistical significance (I $8.0 \pm 1.4 \mathrm{kPa} v s$ IE $7.3 \pm 0.9 \mathrm{kPa} ; \mathrm{p}=0.06$ ). During REM sleep, there were no differences overall in $\mathrm{SaO}_{2} \min$ (I $83.4 \pm 6.7 \%$ vs IE $87.0 \pm 4.5 \%$; $=0.08$ ) or $\mathrm{PtcCO}_{2} \max$ (I $7.7 \pm 1.5 \mathrm{kPa}$ vs IE $7.2 \pm 0.9 \mathrm{kPa} ; \mathrm{p}=0.15)$ but $\mathrm{SaO}_{2} \min$ improved in 4 of the 7 patients and $\mathrm{PtcCO}_{2}$ max was reduced in 5 of the 7 patients.

In the COPD patients, there were no differences in mean (I $8.3 \pm 1.3 \mathrm{kPa} v s$ IE $8.1 \pm 1.6 \mathrm{kPa} ; \mathrm{p}=0.5$ ) or maximum (I 9.0 $\pm 1.4 \mathrm{kPa} v s$ IE $8.9 \pm 1.6 \mathrm{kPa} ; \mathrm{p}=0.7$ ) $\mathrm{PtcCO}_{2}$, or oxygen saturation overnight $\left(\mathrm{SaO}_{2}\right.$ mean I $85.7 \pm 4.6 \%$ vs IE 85.4 $\pm 5.9 \%$; $\mathrm{p}=1.0 ; \mathrm{SaO}_{2}$ min I $67.0 \pm 16.2 \%$ vs IE $65.6 \pm 19.3 \%$; $\mathrm{p}=0.93$ ) (fig. 2 ) or during any sleep stage.

\section{Discussion}

In patients with NMS disorders, the addition of 5 $\mathrm{cmH}_{2} \mathrm{O}$ of EPAP reduced $\mathrm{PtcCO}_{2}$ max and the severity of the largest desaturations. These changes may be important clinically for a number of reasons. It is the largest rise in $\mathrm{CO}_{2}$ during sleep that provokes renal retention of bicarbonate and, hence, has the most effect upon respiratory drive, and the largest falls in $\mathrm{SaO}_{2}$ that have the most physiological impact. Secondly, because daytime respiratory failure may develop gradually over a prolonged period of time [12], the cumulative effect of a small improvement over weeks to months may be much greater. Thirdly, the maximum level of IPAP is usually governed either by the patient's tolerance [13], or by the output of the machine (the Respironics BiPAP can generate a maximum of $22 \mathrm{cmH}_{2} \mathrm{O}$ IPAP) [14]. Therefore, when the control of nocturnal hypoventilation is inadequate with maximum IPAP, adjustment of the level of EPAP may be beneficial. Finally, because the BiPAP delivers a minimum of $2 \mathrm{cmH}_{2} \mathrm{O}$ EPAP, the improvement was seen with a difference of only $3 \mathrm{cmH}_{2} \mathrm{O}$ between the two studies. Therefore, the mandatory $2 \mathrm{cmH}_{2} \mathrm{O}$ of EPAP may be important, and this has implications for the development of future ventilators.

It is possible to speculate about the possible mechanisms of improved gas exchange with EPAP. Functional residual capacity (FRC) falls by up to $30 \%$ in normal subjects on assuming the supine posture [15], and falls further during REM sleep because of loss of intercostal muscle tone $[16,17]$. In scoliotic patients, the straight portion of the S-shaped pressure-volume diagram of the chest is very short [18]; and, therefore, a decrease in FRC means that much larger changes in pressure are necessary to achieve adequate tidal volumes. In addition, if FRC falls below closing capacity there will be an increase in the number of lung units which are perfused but not ventilated, leading to worsening V/Q relationships. PEEP increases FRC and it is likely that EPAP, by reducing or preventing the fall in FRC during sleep, improves the efficiency of inspiratory pressure support and gas exchange.

Reduced lung compliance in scoliosis has been attributed to widespread microatelectasis [19] and/or a generalized change in alveolar surface forces [20,21]. PEEP is thought to recruit collapsed alveoli or improve the compliance of uncollapsed alveoli $[22,23]$, and this may be a further mechanism of benefit from EPAP. Alternatively, the reduced $\mathrm{PtcCO}_{2}$ may, in part, be explained by a lavage effect of continuous expiratory flow in the circuit.

It is possible that differences in sleep quality may explain the improved gas exchange. Although mean $\mathrm{SaO}_{2}$ and $\mathrm{PtcCO}_{2}$ are affected by the duration of sleep, this is not true of $\mathrm{SaO}_{2} \mathrm{~min}$ and $\mathrm{PtcCO}_{2} \mathrm{max}$, which are more likely to be influenced by the duration of each period of uninterrupted sleep. However, there was no significant difference in the longest period of sleep between the two studies. The deterioration in sleep quality during the IPAP/EPAP night in the NMS patients is unlikely to be an effect of acclimatization because the study order was randomized and all patients had had previous experience of the sleep laboratory. Some patients find expiration difficult and uncomfortable with high levels of EPAP and this may have been sufficient to disturb sleep. However, there were no differences in sleep quality in the COPD group.

In the COPD group, there was no benefit from EPAP. Any theoretical benefit of EPAP may have been offset by deleterious effects. IPAP was the same during both studies and, therefore, the addition of EPAP reduced the differential pressure between inspiration and expiration. PEEP may increase end-expiratory lung volume [6], increasing the elastic work of breathing as well as placing the inspiratory muscles at a mechanical disadvantage [24, 25] making assisted breaths less efficient. Any beneficial effects of EPAP reducing inspiratory threshold load and resistive work may be offset by an increase in elastic work and reduced inspiratory muscle efficiency. The level of EPAP chosen may have been too high, compared to PEEPi, during controlled ventilation to improve gas exchange. PEEPi as measured in this study may have been an overestimate because of abdominal muscle activity [26]. Secondly, Rossi et al. [8] found no additional benefit on gas exchange from levels of PEEP greater than $50 \%$ of PEEPi. Finally, EPAP has been shown to have a deleterious effect upon pulmonary haemodynamics and oxygen delivery in patients with COPD [27].

In conclusion, increasing the level of EPAP resulted in a small improvement in the control of nocturnal hypoventilation in patients with NMS disorders. A possible deleterious effect upon sleep quality warrants further investigation. In patients with COPD there was no overall effect.

\section{References}

1. Bergofsky EH, Turino GM, Fishman AP. Cardiorespiratory failure in kyphoscoliosis. Medicine (Baltimore) 1959; 38: 263-317.

2. Sinha R, Bergofsky EH. Prolonged alteration of lung mechanics in kyphoscoliosis by positive pressure hyper- 
inflation. Am Rev Respir Dis 1972; 106: 47-57.

3. Ting EY, Lyons HA. The relation of pressure and volume of the total respiratory system and its components in kyphoscoliosis. Am Rev Respir Dis 1964; 89: 379-386.

4. Katz JA. PEEP and CPAP in perioperative respiratory care. Respir Care 1984; 29: 614-629.

5. Campbell EJM, Dickinson CJ, Dinnick OP, Howell JBL. The immediate effects of threshold loads on the breathing of men and dogs. Clin Sci 1964; 172: 321-331.

6. Nava S, Ambrosino N, Rubini F, et al. Effect of nasal pressure support ventilation and external PEEP on diaphragmatic activity in patients with severe stable COPD. Chest 1993; 103: 143-150.

7. Smith TC, Marini JJ. Impact of PEEP on lung mechanics and work of breathing in severe airflow obstruction. J Appl Physiol 1988; 65: 1488-1499.

8. Rossi A, Santos C, Roca J, Torres A,Felez MA, RodriguezRoisin R. Effects of PEEP on VA/Q mismatching in ventilated patients with chronic airflow obstruction. $A m$ Respir Crit Care Med 1994; 149: 1077-1084.

9. Milic-Emili J, Mead J, Turner JM, Glauser EM. Improved technique for estimating pleural pressures from esophageal balloons. J Appl Physiol 1964; 19: 207-211.

10. Dal Vecchio L, Polese G, Poggi R, Rossi A. "Intrinsic" positive end-expiratory pressure in stable patients with chronic obstructive pulmonary disease. Eur Respir $J$ 1990; 3: 74-80.

11. Rechtschaffen A, Kales A. A manual of standard terminology, techniques and scoring system for sleep stages of human subjects. Bethesda, National Institute of Neurological Disease and Blindness, NIH publication No. 204, 1968.

12. Guilleminault C, Kurlan G, Winkle R, Miles LE. Severe kyphoscoliosis, breathing and sleep: the Quasimodo syndrome during sleep. Chest 1981; 79: 626-630.

13. Waldhorn RE. Nocturnal nasal intermittent positive pressure ventilation with bilevel positive airway pressure (BiPAP) in respiratory failure. Chest 1992; 101: 516-521.

14. Simonds AK, Elliott MW. Use of the BiPAP ventilator for noninvasive ventilation: advantages and limitations. Am Rev Respir Dis 1991; 143 (Suppl.): A585.
15. Marini JJ, Tyler ML, Hudson LD, Davis BS, Huseby JS. Influence of head-dependent positions on lung volume and oxygen saturation in chronic airflow obstruction. $\mathrm{Am}$ Rev Respir Dis 1984; 129: 101-105.

16. Chase MH, Chandler SH, Nakamura Y. Intracellular determination of membrane potential of trigeminal motor neurons during sleep and wakefulness. J Neurophysiol 1980; 44: 349-358.

17. Stradling JR, Chadwick GA, Frew AJ. Changes in ventilation and its components in normal subjects during sleep. Thorax 1985; 40: 364-370.

18. Bergofsky EH. Thoracic Deformities. In: Roussos C, Macklem PT, eds. The Thorax. New York, Marcel Dekker, 1985; pp. 941-978.

19. De Troyer A, Deisser P. The effects of intermittent positive pressure breathing on patients with respiratory muscle weakness. Am Rev Respir Dis 1981; 124: 132-137.

20. Sybrecht GW, Garrett L, Anthonisen NR. Effect of chest strapping on regional lung function. J Appl Physiol 1975; 39: 707-713.

21. Caro CG, Butler J, DuBois AB. Some effects of restriction of chest cage expansion on pulmonary function in man: an experimental study. J Clin Invest 1960; 39: 573-583.

22. Branson RD, Hurst JM, DeHaven CB. Mask CPAP. Respir Care 1985; 30: 846-857.

23. DeHaven CB, Hurst JM, Branson RD. Post-extubation hypoxaemia treated with continuous positive airways pressure mask. Crit Care Med 1985; 13: 46-48.

24. Sharp JT. The chest wall and respiratory muscles in airflow limitation. In: Roussos C, Macklem PT, eds. The Thorax. New York, Marcel Dekker, 1985; pp. 1155- 1212.

25. Macklem PT. Hyperinflation. Am Rev Respir Dis 1984; 129: $1-2$.

26. Ninane V, Yernault JC, De Troyer A. Abdominal muscles, active expiration and intrinsic PEEP (PEEPi) in stable patients with chronic airflow limitation (CAO). Eur Respir J 1992; 5 (Suppl.): 421s.

27. Ambrosino N, Nava S, Torbicki A, et al. Haemodynamic effects of pressure support and PEEP ventilation via nasal route in patients with stable chronic obstructive pulmonary disease. Thorax 1993; 47: 523-528. 